\title{
Effect of Serum Homocysteine on Coronary Artery Disease in Younger and Older Ischaemic Heart Disease Patients.
}

\author{
Kazi Nazrul Islam ${ }^{1}$, Abdul Wadud Chowdhury ${ }^{1}$, Azizul Hasan Khondoker ${ }^{2}$, Md Serajul Haque ${ }^{1}$, \\ KMN Sabah ${ }^{1}$, Md Gaffar Amin ${ }^{1}$, Syed Rezwan Kabir ${ }^{1}$, Mohammed Abaye Deen Saleh ${ }^{1}$ \\ ${ }^{1}$ Department of Cardiology, Dhaka Medical College Hospital, ${ }^{2}$ UHC, Adamdighi, Bogra
}

Key Words :

Age, Coronary Artery Disease, Homocysteine.

\begin{abstract}
:
Background: Hyperhomocysteinemia is known as an independent risk factor of atherosclerosis. But the probable role of Hyperhomocysteinemia in Premature Coronary Artery Disease (CAD) is not well studied. The aim of this study was to assess the role of serum homocysteine on angiographically documented CAD in younger and older ischaemic heart disease (IHD) patients.

Methods: Total 120 patients with IHD admitted in the Department of Cardiology, Dhaka Medical College Hospital for CAG were selected by purposive sampling method and divided into two groups. 60 patients in Group-I, d" 40 years of age (Younger); 60 patients in Group-II, >40 years of age (Older). Homocysteine was measured in all patients and other demographical and clinical data were collected. Homocysteine level was correlated with the presence and severity of CAD.

Results: Smoking, positive family history of IHD, dyslipidaemia and hyper homocysteinemia were important risk factors in younger IHD patients. Whereas, hypertension, diabetes mellitus and dyslipidaemia were important cardiovascular risk factors in older age group. Obesity was not an important risk factors as evidenced by mean BMI. Serum homocysteine was not well related to presence of $C A D$ or extent of CAD in older IHD patients. However in younger patients hyperhomocysteinemia was related to both presence and severity of CAD.

Conclusion: In younger IHD patients hyperhomocysteinemia is an important cardiovascular risk factor. But in older patients it loses its significance. So serum homocysteine level should be screened routinely in younger IHD patients.
\end{abstract}

(Cardiovasc. j. 2016; 8(2): 138-142)

\section{Introduction:}

Hyperhomocysteinemia is an independent risk factor for cardiovascular diseases (CVD) in several groups and high risk subjects. There is a growing recognition that high level of homocysteine is associated with atherosclerotic vascular diseases. This started in the late 1960s when Kilmer McCully, ${ }^{1}$ a pathologist in Boston, encountered two children with elevated plasma homocysteine concentrations and homocystinuria, who, despite being very young, had autopsy evidence of extensive arterial thrombosis and atherosclerosis. On the basis of this observation, he suggested a possible link between homocysteine and the formation of atheromatous plaque. Since McCully hypothesized that elevated plasma homocysteine concentration could cause atherosclerotic vascular disease, several studies have also demonstrated that the presence of moderate hyperhomocysteinemia is an independent risk factor for atherosclerosis in the coronary, cerebral and peripheral vasculature. ${ }^{2,3}$ However whether hyperhomocysteinemia is important in the causation of premature $\mathrm{CAD}$ is not very clear.

\section{Methods:}

This cross sectional comparative study was carried out in the Department of Cardiology, Dhaka Medical College Hospital from October 2009 to September 2010. 120 IHD patients admitted for CAG were divided into two groups. 60 patients in Group-1: $\leq 40$ years of age (younger); and 60 patients in Group-11: >40 years of age (older). Purposive sampling method was followed as per inclusion and exclusion criteria. Data were collected by preformed questionnaire. The cases were evaluated

Address of correspondence: Dr Kazi Nazrul Islam, Department of Cardiology, Dhaka Medical College Hospital, Dhaka, Bangladesh. Email- kazinazrul69@gmail.com. 
through clinical examination and appropriate investigations (e.g. ECG, Chest X-ray, Echocardiography and other relevant investigations). Fasting serum homocysteine was measured in each patient by Fluorescence Polarization Immune-assay [FPIA] detection method. Coronary angiogram was done by right femoral artery approach. Report was reviewed by two cardiologists and CAD was assessed by Vessels score $^{4,5}$ and Friesinger score. ${ }^{6}$

\section{Results:}

In this cross sectional comparative study, we have found that, out of 120 patients, the mean age was $35.4 \pm 4.2$ years and $53.7 \pm 7.3$ years $(\mathrm{p}=0.001)$ in group I and group II respectively. The gender distribution was similar in both groups with males predominating ( $78.3 \%$ vs $21.7 \%$ in group I and $73.3 \%$ vs $26.7 \%$ in group II), ( $\mathrm{p}=0.522)$. Mean BMI was $24.3 \pm 7.3 \mathrm{~kg} / \mathrm{m}^{2}$ in group I and $25.60 \pm 8.2 \mathrm{~kg} / \mathrm{m}^{2}$ in group II (Table- I).

Among the traditional risk factors, younger CAD patients had more family history of premature IHD (21.70\% vs. $8.30 \%, \mathrm{p}=0.040)$ and history of smoking (63.30\% vs. $40.00 \% \mathrm{p}=0.011)$. Older $\mathrm{CAD}$ patients had more hypertension $(41.70 \%$ vs. $65.00 \% \mathrm{p}=0.010)$ and diabetes mellitus ( $18.30 \%$ vs. $36.70 \% \mathrm{p}=0.024)$. Dyslipidaemia was quite high but similar in both groups $(85.00 \%$ vs. $73.30 \% \mathrm{p}=0.955)$ (Table-II).

Hyperhomocysteinemia was found in $1 / 3^{\text {rd }}$ younger CAD patients whereas it was present in only $1 / 8^{\text {th }}$ older CAD patients ( $30.00 \%$ vs. $13.30 \%, \mathrm{p}=0.0260)$. Mean serum homocysteine level was significantly higher in younger CAD patients $(15.1 \pm 8.2$ vs. 11.2 $\pm 7, \mathrm{p}=0.009$ ) (Table- III).

Coronary angiogram showed 15 patients (25\%) in group I had normal or near normal coronaries, whereas only $5(8.33 \%)$ patients in group II had normal coronaries. Double vessel disease (DVD) $(18.30 \%$ vs. $38.30 \%, \mathrm{p}=0.015)$ and triple vessel disease (TVD) $(8.30 \%$ vs. $28.30 \%, \mathrm{p}=0.003)$ were significantly more in older patients (Table-IV).

With normal serum homocysteine level, younger patients had more single vessel disease (SVD) or normal coronaries, but older patients even with normal homocysteine level had more double or triple vessel disease (Table-V).

With hyperhomocysteinemia, younger patients had more SVD or DVD than either TVD or normal

Table-I

Clinical characteristics of patients $(n=120)$.

\begin{tabular}{lccc}
\hline Variables & Group I(n=60) & Group II $(\mathrm{n}=60)$ & p value \\
\hline Age (yrs) & $35.40 \pm 4.20(23-40)$ & $53.70 \pm 7.30(42-70)$ & $0.001^{\mathrm{S}}$ \\
Male (n /\%) & $47(78.30 \%)$ & $44(73.30 \%)$ & $0.522^{\mathrm{NS}}$ \\
Female (n / \%) & $13(21.70 \%)$ & $16(26.70 \%)$ & \\
Mean BMI $\left(\mathrm{Kg} / \mathrm{m}^{2}\right)$ & $24.30 \pm 7.30$ & $25.60 \pm 8.20$ & $0.955^{\mathrm{NS}}$ \\
\hline
\end{tabular}

Group I= $\leq 40$ years; Group II= > 40 years; BMI= Basal Metabolic Index

$\mathrm{NS}=$ Not significant, (gender distribution- $\mathrm{p}$ value reached from chi square test), (BMI-p value reached from independent sample $t$ test)

Table-II

Conventional risk factors analysis of the study patients $(n=120)$.

\begin{tabular}{|c|c|c|c|c|c|}
\hline \multirow[t]{2}{*}{$\overline{\text { Risk factors }}$} & \multicolumn{2}{|c|}{ Group I(n=60) } & \multicolumn{2}{|c|}{ Group II(n=60) } & \multirow[t]{2}{*}{$\mathrm{P}$ value } \\
\hline & $\mathrm{N}$ & $\overline{\%}$ & $\mathrm{n}$ & $\%$ & \\
\hline Smoking & 38 & 63.3 & 24 & 40.0 & $0.011^{\mathrm{S}}$ \\
\hline Hypertension & 25 & 41.7 & 39 & 65.0 & $0.010^{\mathrm{S}}$ \\
\hline Diabetes mellitus & 11 & 18.3 & 22 & 36.7 & $0.024^{\mathrm{S}}$ \\
\hline Dyslipidaemia & 51 & 85.0 & 44 & 73.3 & $0.115^{\mathrm{NS}}$ \\
\hline Family history of CAD & 13 & 21.7 & 5 & 8.3 & $0.040^{\mathrm{S}}$ \\
\hline
\end{tabular}

$\mathrm{S}=$ significant, $\mathrm{NS}=$ not significant;

$\mathrm{P}$ value reached from chi square test 
Table III

Serum Homocysteine status of the study patients $(n=120)$.

\begin{tabular}{lccccc}
\hline Serum homocysteine & \multicolumn{2}{c}{ Group I $(\mathrm{n}=60)$} & \multicolumn{2}{c}{ Group II $(\mathrm{n}=60)$} & p value \\
& $\mathrm{N}$ & $\%$ & $\mathrm{n}$ & $\%$ & \\
\hline Normal $(5-15 \mathrm{mmol} / \mathrm{L})$ & 42 & 70.0 & 52 & 86.7 & $0.026^{\mathrm{S}}$ \\
High(>15mmol/L) & 18 & 30.0 & 8 & 13.3 & \\
Mean fasting serum & 15.1 & \pm 8.2 & 11.2 & \pm 7.8 & $0.009^{\mathrm{S}}$ \\
homocysteine(mmol/L) & & & & & \\
\hline
\end{tabular}

$\mathrm{S}=$ significant, (serum homocysteine- $\mathrm{p}$ value reached from chi square test), (Mean fasting serum homocysteine- $\mathrm{p}$ value reached from unpaired test)

Table-IV

Comparative analysis of angiographic profile between the two groups $(n=120)$.

\begin{tabular}{llccccc}
\hline vessel score & No of vessel & \multicolumn{2}{c}{ Group I(n=60) } & \multicolumn{2}{c}{ Group II(n=60) } & p value \\
& & $\mathrm{N}$ & $\%$ & $\mathrm{~N}$ & $\%$ & \\
\hline 0 & Normal coronary artery & 15 & 25.0 & 5 & 8.3 & $0.022^{\mathrm{S}}$ \\
1 & single vessel disease (SVD) & 29 & 48.3 & 15 & 25.0 & $0.007^{\mathrm{S}}$ \\
2 & Double vessel disease (DVD) & 11 & 18.3 & 23 & 38.3 & $0.015^{\mathrm{S}}$ \\
3 & Triple vessel disease (TVD) & 5 & 8.3 & 17 & 28.3 & $0.004^{\mathrm{S}}$ \\
\hline
\end{tabular}

$\mathrm{S}=$ significant, $\mathrm{p}$ value reached from chi square test

Table-V

Patients with normal serum homocysteine level and their angiographic profile by vessel score $(n=94)$.

\begin{tabular}{llccccc}
\hline Vessel score & No of Vessel & \multicolumn{2}{c}{ Group I $(\mathrm{n}=42)$} & \multicolumn{2}{c}{ Group II (n=52) } & p Value \\
& & $\mathrm{N}$ & $\%$ & $\mathrm{~N}$ & $\%$ & \\
\hline 0 & Normal coronary artery & 13 & 30.9 & 3 & 7.8 & $0.001^{\mathrm{S}}$ \\
1 & Single vessel disease (SVD) & 21 & 50.0 & 12 & 23.0 & $0.007^{\mathrm{S}}$ \\
2 & Double vessel disease (DVD) & 6 & 14.3 & 21 & 40.4 & $0.005^{\mathrm{S}}$ \\
3 & Triple vessel disease (TVD) & 2 & 4.8 & 16 & 30.8 & $0.001^{\mathrm{S}}$ \\
\hline
\end{tabular}

$\mathrm{S}=$ significant, $\mathrm{p}$ value reached from chi square test

coronaries. Older CAD patients with either normal or raised serum homocysteine level had more DVD and TVD (Table-VI).

When assessing extent of CAD by Friesinger score, younger patients with normal homocysteine level have low score $(<5)(83.3 \%$ vs16.7\%) but with hyperhomocysteinemia they have mostly high
Friesinger score $\left.{ }^{3} 5\right)(38.90 \%$ vs. $61.10 \%)$ indicating more extensive $\mathrm{CAD}$. Older $\mathrm{CAD}$ patients however showed higher Friesinger score in both normal homocysteine group (30.80\% vs. $69.20 \%)$ and hyperhomocysteinemia group (50\% vs. $50 \%)$ suggesting no correlation between level of serum homocysteine and extent of CAD in older age group(Table-VII, VIII).

Table-VI

Patients with high serum homocysteine level and their angiographic profile by vessel score $(n=26)$.

\begin{tabular}{|c|c|c|c|c|c|c|}
\hline \multirow[t]{2}{*}{ Vessel score } & \multirow[t]{2}{*}{ No of vessel } & \multicolumn{2}{|c|}{ Group I (n=18) } & \multicolumn{2}{|c|}{ Group II (n=8) } & \multirow[t]{2}{*}{ p Value } \\
\hline & & $\mathrm{N}$ & $\%$ & $\mathrm{~N}$ & $\%$ & \\
\hline$\overline{0}$ & Normal coronary artery & 2 & 11.1 & 2 & 25.0 & $0.359^{\mathrm{NS}}$ \\
\hline 1 & single vessel disease (SVD) & 10 & 55.5 & 1 & 12.5 & $0.049^{\mathrm{S}}$ \\
\hline 2 & Double vessel disease (DVD) & 5 & 27.8 & 2 & 25.0 & $0.639^{\mathrm{NS}}$ \\
\hline 3 & Triple vessel disease (TVD) & 1 & 5.5 & 3 & 37.5 & $0.072^{\mathrm{NS}}$ \\
\hline
\end{tabular}

$\mathrm{S}=$ significant, $\mathrm{NS}=$ not significant $\mathrm{p}$ value reached from fishers extact test 


\section{Discussion:}

The plasma level of homocysteine is an independent risk factor for atherosclerotic vascular disease. ${ }^{5,6}$ Homocysteine is present in serum as free homocysteine (1\%), as a homocysteinedisulfide (10\%), homocysteine-cysteine mixed disulfide (10\%) or as protein-bound form (70-80\%) mainly to albumin. ${ }^{7}$ Normal total serum homocysteine concentration (tHcy) ranges from 5 to $15 \mu \mathrm{mol}$ per liter in the fasting state. ${ }^{8}$ Elevated serum homocysteine level is referred to as "Hyperhomocysteinemia". An abnormal total homocysteine (tHcy) is defined by an arbitrary cutoff (95th percentile), of the concentrations found in normal population. Hyperhomocysteinemia has been classified as: moderate (tHcy $>15$ to $30 \mu \mathrm{mol} /$ $\mathrm{L}$ ), intermediate (tHcy $>30$ to $100 . \mu \mathrm{mol} / \mathrm{L}$ ) and severe $(\mathrm{tHcy}>100 \mu \mathrm{mol} / \mathrm{L})$ on the basis of the concentrations measured during fasting. ${ }^{9}$

Serum homocysteine concentrations are influenced by age, gender, genetic, nutritional and acquired factors. ${ }^{10}$ tHcy increases with age \& is about $20 \%$ greater in young and middle aged men than in women of comparable age. ${ }^{11}$ Cystathionine -synthase deficiency is the most common genetic cause of severe hyperhomocysteinemia; Nutritional deficiencies in the vitamin cofactors (folate, vitamins B6 and B12) may promote hyperhomocysteinemia. ${ }^{7}$

Raised plasma homocysteine to be a potential risk factor for ischaemic heart disease. ${ }^{12}$ Homocysteine accumulation could result from B-vitamin deficiency which is related to chronic immune activation. ${ }^{13}$ Hyperhomocysteinemia is an independent risk factor for IHD in young patients especially in men and vitamin B12 deficiency is a preventable cause of hyperhomocysteinemia. ${ }^{7}$

In our cross sectional study, we found mean serum homocysteine level was significantly higher in younger age group $(15.1 \pm 8.2 \mathrm{mmol} / \mathrm{L}$ vs. $11.2 \pm 7.8$ $\mathrm{mmol} / \mathrm{L}, \mathrm{p}=0.009)$. Kawashiri et al. ${ }^{14}$ reported that plasma homocysteine level of subjects in younger IHD group was significantly higher than that of subjects in older IHD group (15.0 vs $11.3 \mathrm{nmol} / \mathrm{ml}$, $\mathrm{p}=0.03)$. Sadeghian et al. ${ }^{15}$ concluded that hyperhomocysteinemia is an independent risk factor for CAD in young, especially in men.

Gender distribution in this study groups showed more male in younger IHD group (M: $\mathrm{F}=3.6: 1$ in group I and 2.8:1 in group-II). This is expected because of the protective effect of female gender in premature CAD. Tewari et al. ${ }^{16}$ observed similar sex ratio in their study.

Among the traditional risk factors, younger IHD patients had significantly higher family history of IHD $(21.70 \%$ vs. $8.30 \%, p=0.040)$ and history of smoking $(63.30 \%$ vs. $40.00 \%, p=0.011)$. Older patients had more hypertension $(41.70 \%$ vs. $65.00 \%, \mathrm{p}=0.010)$ and diabetes mellitus $(18.30 \% \mathrm{vs}$. $36.70 \% \mathrm{p}=0.024$ ). Dyslipidemia was similarly higher in both groups. Schoenenberger et al. ${ }^{17}$ mentioned that smoking, family history of $\mathrm{CAD}$, dyslipidemia are important cardiovascular risk factors in young patients. Tewari et al. ${ }^{16}$ and Majumder et al. ${ }^{18}$ were also made the similar observations.

Mean BMI was however similar in both groups $(24.3 \pm 7.3 \mathrm{~kg} / \mathrm{m} 2$ vs. $25.0 \pm 8.2 \mathrm{~kg} / \mathrm{m} 2 \mathrm{p}=0.955)$ and was not high in either groups. This is indicating obesity as a risk factor was not important as a whole in our patients. Pradeep et $\mathrm{al}^{19}$ found similar BMI in their study, which are consistent with the present study. ${ }^{19}$ Tewari et al. in their study observed mean BMI $23.7 \pm 2.42(\mathrm{~kg} / \mathrm{m} 2)$ in younger group and $24.9 \pm 2.17$ in older group. ${ }^{16}$

When considering severity of CAD in younger and older groups, it was found younger patients had more normal or near normal coronary arteries ( $25.00 \%$ vs. $8.30 \%, \mathrm{p}=0.022)$ or single vessel disease ( $48.30 \%$ vs. $25.00 \%$, p=0.015). But older patients had more DVD (18.30\% vs. $38.30 \%, \mathrm{p}=0.015)$ and TVD ( $8.30 \%$ vs. $28.30 \%, p=0.0 .004)$. This finding correlates well with clinical presentation of the study patients, where older patients had more MI (STEMI or NSTEMI) and younger patients had more CSA.

Raised serum homocysteine level was found in $30.00 \%$ younger IHD patients and only $13.30 \%$ older IHD patients $(p=0.026)$. However, when considering serum homocysteine level as on CAD predisposing risk factor it was found that older patients do not show much difference in extend of CAD. They have more DVD or TVD in both normal homocysteine group (71.2\%) and hyperhomocysteinemia group $(62.50 \%)$. On the other hand, younger patients showed more normal coronaries in normal homocysteine group (30.90\%) than in higher homocysteine group (11.10\%). They have more DVD or TVD in hyperhomocysteinemia group (19.10\% vs. $33.30 \%)$. 
Using Friesinger score, it was seen that older patients had high Friesinger score $\left({ }^{3} 5\right)$ in both normal homocysteine group (69.20\%) and high homocysteine group (50.00\%). But younger patients with normal homocysteine level have mostly low score (0-4) (83.30\%) and mostly high Friesinger score $\left({ }^{3} 5\right)$ in hyperhomocysteinemia group (61.10\%). Bampi et al. observed that, Friesinger score $0-4$ indicates less extensive coronary artery disease and Friesinger score ${ }^{3} 5$ indicates extensive coronary atherosclerosis with extensive coronary artery disease. ${ }^{6}$ These results showed that in older patient's serum homocysteine level do not correlate well with number of coronary vessels involved or with the extent of CAD. Whereas in younger patients hyperhomocysteinemia is related more to the presence of CAD and extent of CAD. In their study Tewari et al. found SVD 61.18\% in group-I (younger patients) and $45.56 \%$ in group-II (older patients), DVD (23.28\% vs. $32.35 \%)$ and TVD (14.61\% vs. 21.3 $2 \%)$. These findings were similar to our study. ${ }^{16}$

\section{Conclusion:}

This study showed that hyperhomcysteinemia is associated with more extensive $\mathrm{CAD}$ In younger IHD patients only. Whereas, in older IHD patients it does not have any significant impact on the presence or the extent of CAD. So we should routinely screen for serum homocysteine level in younger ( $<40$ years) IHD patients. As folate and vitamin B12 supplementation can easily prevent hyperhomocysteinemia, proper diatery advice should be used to prevent premature CAD.

\section{Conflict of Interest - None.}

\section{References:}

1. McCully KS. Vascular pathology of homocysteinemia: implications for the pathogenesis of arteriosclerosis. Am J Pathol 1969; 56:111-128.

2. Stampfer MJ, Malinow MR. Can lowering homocysteine levels reduces cardiovascular risk?. N Engl J Med 1995;332:328-329.

3. Graham IM, Daly LE, Refsum HM. Plasma homocysteine as a risk factor for vascular disease: the European Concerted Action Project. JAMA 1997; 277:1775-1781.

4. Chaitman BR, Bourassa MG, Davis K, Rogers WJ, Tyras DH, Berger R, Kennedy JW. Angiographic prevalence of high-risk coronary artery disease in patient Subsets. Circulation 1981; 64:360-367.

5. Sullivan DR, ThomasH, Marwick S, Ben Freedman. A new method of scoring coronary angiograms to reflect extent of coronary atherosclerosis and improve correlation with major risk factors. Am Heart J 1990; 119(6):1262-1267.
6. Bampi ABA, Rochitee CE, Favarato D, Lemos PA, Luz PLD. Comparison of non-invasive methods for the detection of coronary atherosclerosis. Clinics (Sao Paulo) 2009; 64(6):675-682.

7. Guthikonda S, Haynes WG. Homocysteine as a novel risk factor for atherosclerosis. Curr Opin Cardiol1999; 14: 283-291.

8. Puri A, Gupta OK, Dwivedi RN. Homocysteine and Lipid levels in young patients with coronary artery disease. JAPI 2003; 51:681-685.

9. Kang SS, Wong PW, Malinow MR. Hyperhomocyst(e)inemia as a risk factor for occlusive vascular disease. Annu Rev Nutr 1992;12:279-298.

10. Hankey JH, Eikelboom JW. Homocysteine and vascular disease. Lancet 1999; 354:407-413.

11. Brattstrom L., Lindgren A., Israelsson B. Homocysteine and cysteine: determinants of plasma levels in middleaged and elderly subjects. J Intern Med 1994; 1(236):633641.

12. Kabir MS, Majumder AAS, Chowdhury AW, Haque SA, Reza AQM, Islam AEMM. Raised plasma homocysteine: An emerging risk factor for ischaemic heart disease. TAJ December 2006; 19(2):87-93.

13. Schroecksnadel K, Grammer TB, Boehm BO, Marz W, Fuchs D. Total homocysteine in patients with angiographic coronary artery disease correlates with inflammations markers. Thromb Haemostasis 2010; 103:926-935.

14. Kawashiri M, Kajinami K, Nohara A, Yagi K, Inazu A, Koizumi J. Plasma homocysteine level and development of coronary artery disease. Coronary Artery Dis 1999; 10(7):443-447.

15. Sadeghain S, Fallah F, Salarifar M, Davoodi G, Mahoodian M, Fallah N. Homocysteine, vitamin B12 and folate levels in premature coronary artery disease. BMC Cardiovascular Disoders 2006; 6:38.

16. Tewari S, Kumar S, Kapoor A, Singh U, Agarwal A, Bharti BB. Premature-coronary-artery disease in North India: An angiography study of 1971 patients. Indian Heart J 2005; 57: 311-318. 16.

17. Barden HM, Elnoamany MF, Khalil TS, Eldin MME. Age-related alteration of risk profile, inflammatory response, and angiographic findings in patients with acute coronary syndrome. Clinical Medicine: Cardiology 2009; 3:15-28.

18. Schoenenberger AW, Radovanovic D, Stauffer JC, Windecker S, Urban P, Niedemaier G, et al. Acute coronary syndromes in young patients presentation treatment and outcome. Int J Cardiol 2009; 15:2.

19. Majumder AAS, Atahar Ali M, Saha GK. Comparison of risk factor prevalence and complications between early onset and late onset acute myocardial infarction'patients presentation, treatment and outcome. Bangladesh Heart Journal 2000; 15(2):77-80.

20. Pradeep KN, Haritha PS, Krisman NR, Umesan CV, Joseph PK, Chandrakumar J, et al. Comparison of coronary artery profile in young and old patients with coronary artery disease and its correlation with coronary risk factors. Indian Heart $J$ 2004; 56:412. 